\title{
Hastalığı modifiye eden antiromatizmal ilaçlarla etkileşimler bakımından analjezik ilaçların akılcı kullanımı
}

\author{
Rational use of analgesics with regard to the interactions with disease-modifying \\ anti-rheumatic drugs
}

Aytül Önal(D)

Ege Üniversitesi Tıp Fakültesi, Tıbbi Farmakoloji Anabilim Dalı

\begin{abstract}
Öz
İnflamatuar nitelikli romatizmal hastalıklarda, analjezikler özellikle de NSAil'ler "Hastalığı modifiye eden antiromatizmal ilaçlar (Disease-Modifying Anti-Rheumatic drugs; DMARDs)" ile birlikte sıklıkla kullanılan ilaçlardandır. Söz konusu ilaçlar arasındaki etkileşimler ile ilgili yapılmış kontrollü çalışmalar çok değildir ve daha çok metotreksat ve NSAil'ler arasındaki etkileşimler ile ilgilidir. Özellikle son yıllarda kullanımı artan biyolojik DMARD'ler ile analjezik ilaçlar arasındaki etkileşmelere yönelik kontrollü araştırmalara büyük intiyaç vardır. Derlememizde, DMARD'ler ile analjezik ilaçlar arasındaki etkileşimler bakımından akılcı ilaç kullanımından söz edilmiştir. Bu etkileşimler, proteine bağlanma, renal, gastrointestinal, hematolojik, hepatik fonksiyonlar ve enzim düzeyindeki değişimler ile ilgili alt başlıklar şeklinde sunulmuştur.
\end{abstract}

Anahtar Sözcükler: Hastalık modifiye eden antiromatizmal ilaçlar, analjezik ilaçlar, nonsteroid antiinflamatuar ilaçlar, ilaç etkileşimi.

\begin{abstract}
In the inflammatory rheumatic diseases, analgesics, especially the NSAIDs are the most used drugs with the disease-modifying anti-rheumatic drugs (DMARDs). The controlled studies which were done related with the interactions between the aforementioned drugs are not too many and they are more related with interactions between methotrexate and NSAIDs. Controlled studies are mostly needed related with the interactions between analgesic drugs and biologic DMARDs which were especially came into use in the recent years. In our review, rational use of drugs was mentioned with regard to the interaction between DMARDs and analgesic drugs. These interactions were presented as subtitles related with changes in binding to proteins, renal, gastrointestinal system, hematologic, hepatic functions and the levels of enzymes.
\end{abstract}

Keywords: Disease-modifying anti-rheumatic drugs, analgesic drugs, non-steroidal anti-inflammatory drugs, drug interaction.

\section{Giriş}

Romatizmal hastalıkların yaklaşık \%10 kadarını romatoid artrit gibi inflamatuar bulguların ön planda olduğu patolojiler oluşturmaktadır. İmmünoloji, genetik, moleküler biyoloji ve mikrobiyoloji alanlarındaki yenilikler ile söz konusu hastalıkların patogenezi daha iyi anlaşıımıştır (1). Son 20 yıldaki bu önemli gelişmelere paralel olarak, inflamatuar romatizmal hastalıkların tedavisinde kullanılan ilaçların akılcı kullanımının önemi de artmıştır. Akılcı ilaç kullanımı, Dünya Sağıık Örgütü'nün 1985 yılında Nairobi'de tanımlamış olduğu şekliyle "kişilerin klinik bulgularına ve bireysel özelliklerine göre uygun ilacı, uygun süre ve dozda, en uygun maliyetle ve kolayca sağlayabilmeleridir” (2).

\footnotetext{
Yazışma Adresi: Aytül Önal

Ege Üniversitesi Tıp Fakültesi Tıbbi Farmakoloji Anabilim Dalı E-mail: aytul.onal@ege.edu.tr
}

Bir ilaç, başka bir ilacın etkisini nitel ya da nicel olarak değiştiriyorsa bu iki ilaç etkileşiyor demektir. Etkileşme bazen, bir ilacın terapötik etkisini diğer bir ilaçla artırmak ya da yan etkisini azaltmak için, istenerek; bazı durumlarda ise, ilaçların yeterli bilgi olmadan kullanılması ya da hastanın kullandığı başka ilaçların dikkate alınmaması sonucu, istenmeden olabilir. Bunlar genellikle zararlı, bazen de ciddi tehlikeler yaratabilecek etkileşimlerdir (3). Hastaneye yatış gerektiren advers ilaç reaksiyonlarının \%10-20'sini oluşturan bu durumun önlenebilir olması nedeni ile zararlı ilaç-ilaç etkileşimlerinin farkında olmak önemlidir. İlaç-ilaç etkileşiminin nasıl oluştuğunun ve bunun nasıl yönetileceğinin bilinmesi, klinikte akılcı ilaç uygulamalarının önemli hedeflerindendir (4).

İnflamatuar bulgularla seyreden romatizmal hastalıkların farmakolojik tedavisinde, başta Nonsteroid antiinflamatuar ilaçlar (NSAii) olmak üzere kullanılan analjezik ilaçlar, daha çok semptomatik rahatlatmaya yönelik ilaçlardır. Söz 
konusu ilaçların eklem deformitesinin ilerlemesine etkileri çok azdır. Günümüzde romatoid artrit yanında ankilozan spondilit, psoriyatik artrit ve sistemik lupus eritematoz gibi diğer romatizmal hastalıklarda da kullanılmakta olan “Hastalığı Modifiye Eden Antiromatizmal İlaçlar (DiseaseModifying Anti-Rheumatic Drugs-DMARDs)" ise hastalığın etkilerini azaltarak artritik doku yıkımının ilerlemesini geciktirir ve bu ilaçların hepsinin etki mekanizmaları farklıdır. Bu nedenle gereken hastalarda kombine olarak kullanılabilir. Etkileri yavaş başlar ve ilaç kesildikten sonra da bir süre daha devam eder. Bu ilaçların en önemlisi metotreksattır. Günümüzde sık kullanılan diğer klasik DMARD'lar, antimalaryal ilaçlar (klorokin ve hidroksiklorokin), sulfasalazin ve leflunomiddir. Son yıllarda romatizmal hastalıklarda kullanımları giderek azalan diğer klasik DMARD'lar ise siklosporin, altın tuzları, D-penisilamin, azatioprin ve siklofosfamiddir. Uzun yıllardır kullanılan klasik DMARD'lara son 10-15 yılda infliksimab, etanersept, adalimumab, golimumab, sertolizumab, abatasept ve rituksimab gibi birçok yeni biyolojik ilaç, bu ilaçların biyo benzerleri ve tofasitinib gibi biyolojik bir ilaç olmamasına karşın etki mekanizması biyolojiklere benzeyen yeni sentetik DMARD'lar da eklenmiştir. Bunlar dışında anakinra, kanakinumab, rilonasept, gevokizumab, tosiluzumab, belimumab, sekukinab gibi kullanıma yeni giren veya girmek üzere olan biyolojik ajanlar da mevcuttur. Söz konusu biyolojik ajanlar özellikle konvansiyonel tedavilere dirençli, inatçı orta veya yüksek hastalık aktivitesi olan ve prognozun iyi olmadığına dair göstergelerin bulunduğu hastalarda önemli bir tedavi alternatifi oluşturmaktadır (5-7). Romatolojik hastalıklar, özellikle akciğer ve böbrek gibi organ tutulumları varsa önemli morbidite ve mortaliteye neden olabilmektedir. Kortizonun keşfi ve romatolojide kullanımı bu sorunların tedavisinde çığır açsa da doz azaltıldığında hastalığın nüksetmesi ve kortikosteroidlerin yan etkileri nedeniyle tedavide çoğunlukla eş zamanlı immünosüpresif ilaçlar kullanılmaktadır (8).

Romatizmal hastalıklarda DMARD'ler ile birlikte kullanılan ilaçların başında analjezik ilaçlar ve özellikle de NSAil'ler gelmektedir. İnflamatuar artrit tipi, başka inflamasyon varlığı, eşlik eden hastalıklar, hasta tercihi, kullanılan başka ilaçlar göz önünde bulundurulduğunda, romatizmal hastalıkların ağrı yönetiminde, ilk tercih NSAii veya parasetamol, ikinci tercih NSAil+parasetamol dür. NSAil ve parasetamol yetersiz kaldığında ya da kontrendike olduğunda zayıf etkili opioid ilaçlar, tercih edilebilecek ilaç grubudur (9). Nöromodülatör ve antidepresan ilaç kullanımı daha tartışmalı ve zayıf seçenek olarak kalırken, pregabalin ya da gabapentin de adjuvan terapi seçeneği olabilir. Analjezik ilaçlarla yapılan çalışmaların çoğu, hastaların DMARD almadığı ya da biyolojik DMARD'lerin kullanımının başlamadığı 1990'ı yıllarda yapılmış araştırmalardır ve inflamasyonlu artritte analjezik ilaçların söz konusu ilaçlar ile kombinasyonu konusunda kontrollü yapılmış çalışmalar yeterli değildir. Bu ilaçlarla birlikte hastaların güvenli analjezik kullanımı ile ilgili başka çalışmalara intiyaç vardır (10).

NSAil'lerin ağız yolundan alınmalarının ardından hızla emilirler ve doruk plazma derişimlerine 2-3 saat içinde ulaşırlar. Diklofenak ve nabumeton gibi bazı bileşikler ilkgeçiş etkisine veya presistemik eliminasyona uğrarlar. NSAil'lerin çoğu yüksek oranda (\%95-99) plazma proteinlerine bağlanırlar. Genellikle hemodiyaliz ile uzaklaştırılamazlar. Çoğu büyük ölçüde vücudun her yerine dağılır ve artritli eklemlere kolayca geçer, sinoviyal sıvıdaki derişimleri plazmadaki derişimlerin yarısına kadar ulaşabilir (örn. ibuprofen, naproksen, piroksikam). Söz konusu ilaçların plazma yarı ömürleri çok değişkendir. Piroksikam 50 saat, ibuprofen, diklofenak ve asetominofenin 1-4 saattir. COX-2 seçicilerden olan lumirakoksib 2-6 saat, selekoksib 6-12 saat, etorikoksibise 20-26 saatdir. Karaciğer biyotransformasyon ve böbrekler yoluyla atılma NSAil'lerin çoğu için esas metabolizma ve eliminasyon yollarıdır $(5,11)$.

Anjiyotensin konverting enzim inhibitörleri, varfarin, aminoglikozidler; fenitoin, kortikosteroidler, digoksin, sülfonilüreler ve diüretikler gibi birçok ilaçla etkileşim gösteren NSAil'ler gibi diğer bir analjezik ilaç grubu olan opioidlerin de özellikle enzim düzeyinde olmak üzere birçok ilaçla etkileşimi bulunmaktadır $(5,12)$. Fakat DMARD'ler ile analjezik ilaçlar arasındaki etkileşimlerle ilgili aşağıda ayrıntıları verilen hayvan ve insan farmakokinetik çalışmaları ile klinik gözlemlere dayanan araştırmalar daha çok NSAil'lerle ilgilidir ve opioid ilaçlar ya da adjuvan analjezikler arasında etkileşime dikkat çeken önemli bir çalışma ya da klinik gözlem bulunmamaktadır (10)

\section{Proteine Bağlanma ile İlişkili Etkileşimler}

Çeşitli klinik gözlemlerde, metotreksat ile indometazin $(13,14)$, ibuprofen (15), ketoprofen (16), naproksen (17), fenilbutazon (18), azapropazon (19) ve salisilatlar (20) gibi NSAli'lerin birlikte kullanıldığı hastalarda kemik iliği depresyonu, mukoza iltihapları hepatit ve renal yetmezlik gibi toksik etkilerde bir artış olduğu görülmüştür. Bu toksik etkilerin olası mekanizmaları, metotreksatın proteine bağlanan alanlardan ayrılarak bağlı olmayan serum seviyelerin artması ve NSAlilerin prostaglandin sentez inhibisyonu ile metotreksatın renal klirenslerinin artışına neden olmalarıdır (21).

NSAililer plazma proteinlerine yüksek oranda bağlandığı için başka ilaçları bağlanma yerlerinden ayırabilirler. Bu türdeki etkileşmelerin metotreksat ile birlikte NSAil'lerin verildiği hastalarda görülme olasılığı yüksek olduğundan, toksisiteyi önlemek için bu ajanların dozajlarının ayarlanması gerekebilir. Özellikle salisilatlar ve fenilbutazon gibi proteine bağlanma oranı yüksek NSAil'ler, metotreksatı serum albüminine bağlandığı 
yerden uzaklaştırıp biyoyararlanımını daha fazla artırarak dolaylı bir doz artışına yol açarlar (5, 21-24).

Tolmetin, naproksen (1000mg/gün), indometazin veya aspirin kullanılan romatoid artrit ve tümörlü hastalarda yapılan klinik çalışmalarda, aspirinin, 5-15 mg dozunda verilmiş metotreksatın klirensini \%20-35 düşürdüğü gösterilmiş ise de söz konusu NSAil'lerin bu dozlardaki metotreksat ile kinetik ve klinik parametrelerde anlamlı bir değişiklik oluşturmadığı gözlenmiştir (20, 25-27). Yakın tıbbi gözetim sağlandığı sürece düşük dozlu metotreksat ile romatoid artrit tedavisine eş zamanlı olarak bu gibi ilaçlar eklenebilir. Bununla birlikte düşük doz metotreksat uygulanan özellikle yaşlı ve böbrek yetmezliği olan hastalarda NSAil ile metotreksat arasındaki olası bir etkileşim riski göz önünde bulundurulmalıdır. Böyle hastalarda kombine bir tedavinin gerekli olması durumunda kan tablosu ile böbrek işlevi ve karaciğer fonksiyonlarının gözlemlenmesi gerekmektedir. Özellikle 12-24 saatlik bir periyod içerisinde NSAII ile metotreksat verilmesi durumunda dikkat edilmelidir, çünkü bu durumda metotreksat plazma seviyesi yükselebilir ve toksisite artar. Yüksek dozlarda (>15 mg/hafta) metotreksat uygulandığında, muhtemelen NSAil'lerin proteine bağlı metotreksatın yerini alması ve metotreksatın renal klerensinin azalması ile ilişkili olarak hematolojik toksisite riskinde artış görülür. Düşük doz metotreksat verilmesini takiben 12-24 saat içinde NSAli'lerin verilmesi güvenli iken yüksek doz metotreksata başlanmadan en az 10 gün içinde NSAil ilaçların kesilmesi gerekmektedir (26, 28, 29).

Metotreksat kullanan inflamatuar artritli hastalarda NSAil (aspirin, parasetamol, etodolak, piroksikam, selekoksib ve eterokoksib) kullanımının güvenliği konusu ile ilgili daha sonraki yıllarda yapılan bir Cochran çalışmasında (2011), söz konusu NSAil'lerin akciğer problemlerini artırmadığı fakat yüksek doz aspirinin (günde $2 \mathrm{mg}$ ) metotreksata bağlı renal ve karaciğer problemlerini artırabileceği, metotreksata bağlı kan problemlerini (düşük trombosit gibi) orta derecede yükseltebileceği (özellikle metotreksatın aynı gün alınmasıyla), ancak bu birlikte kullanımın hastanın metotreksatı kesmeyi gerektirmediği bildirilmiştir. On yedi çalışma incelenerek yapılan söz konusu çalışmada parasetamol ile metotreksatın kullanımı ile ilgili inklüzyon tanımlaması yapan bir çalışmaya da rastlanılmadığı bildirilmiştir (30).

\section{Renal Fonksiyonlar ile İlişkili Etkileşimler}

Prostaglandinler renal vasküler yatakta dilatasyona neden olurlar (31). Endojen prostaglandinler, normal koşullardan daha çok renal vazokoksriksiyonun olduğu koşullarda böbrek fonksiyonunu devam ettirmeye çalışırlar $(32,33)$. Adrenerjik ve renin-anjiotensin gibi pressör mekanizmaların aktivasyonu ile volüm azalması görülür $(34,35)$. Bu mekanizmaların vazokonstrüktif etkisi, vazodilatör renal prostaglandinlerin aynı zamanda uyarılmasıyla azaltılır. NSAil'ler bu kompensatuvar mekanizmaya müdahale ederler ve böylece renal kan akımı azalır $(32,34)$. Sulindak, naproksen, diklofenak ve indometazin gibi NSAli'lerin siklosporin ile birlikte kullanılarak yapıldığı çalışmalarda, iki haftada belirginleşen ve 20 haftaya kadar sürebilen glomerüler filtrasyon hızı (GFH), renal kan akımı ve hafif derecede filtrasyon fraksiyonu azalması gibi renal fonksiyonlarda ve sabah erken renin-aldosteron sistem değerlerinde azalma görülmüştür (36-39). Ayrıca renal prostasiklin sentezinde azalmaya bağlı olaraksiklosporin toksisitesinde artış olabileceği bildirilmiştir (36, 40). Deneysel çalışmalarda ise, indometazin ile siklosporinin birlikte kullanımı ile mortalitenin artığı (41) ve daha çok nefrotoksisite nedenli söz konusu bu etkileşimin $\mathrm{ET}_{\mathrm{A}}$ reseptörleri ile ilişkili olduğu (42) gösterilmiştir. NSAII tarafından böbrekte prostaglandin sentezi inhibisyonu, siklosporinin nefrotoksik etkisinden korunmak için gerekli olan GFH ve renal kan akımını azaltır. Bu durumun siklosporin ve NSAillerin ikisinin de renal antiprostaglandin etkilerinin birleşmesinden dolayı olabileceği düşünülmektedir. Geri dönüşümlü ve kısmen renal vazokonstrüksiyonla ilişkili olduğu bildirilen söz konusu renal fonksiyon değişiminin, olası nefrotoksisite riskinde artış nedeniyle özellikle de yaşlı hastalarda dikkatli izlenilmesi gerekmektedir (39).

Romatoid artritli hastalarda yapılan başka klinik çalışmalarda, diklofenak ile siklosporinin birlikte kullanımı sonucu diklofenak biyoyararlanımında anlamlı bir artışla birlikte renal fonksiyonlarda olası bir bozulmaya dikkat çekilmiştir. Diklofenakın biyoyararlanımındaki artış, olasılıkla onun yüksek ilkgeçiş etkisinin azalması nedeniyledir. Yüksek ilk-geçiş metabolizmasına sahip NSAil'ler, siklosporin kullanacak hastalarda daha düşük dozda uygulanmalıdır. Eğer düşük ilk-geçiş etkisine sahip NSAliler (örn.: asetil salisilik asit) siklosporinle birlikte verilirse, genellikle söz konusu ilaçların biyoyararlanımlarında artış beklenmez (43).

Muhtemelen vazokonstriksiyon/vazodilatasyon dengesi, inflamatuar, oksidatif, fibrotik ve apopitotik süreçlerle ilişkili olmak üzere, COX2 selektif etkili selekoksibin, siklosporinin renal ve kardiyovasküler yan etkileri üzerinde daha pozitif dengeleyici özelliği bulunmaktadır $(44,45)$. Fakat yine de selekoksibin, siklosporin veya takrolimus gibi ilaçlardan biriyle kombine edildiğinde böbrek fonksiyonunun izlenmesi önerilmektedir

Biyoyararlanımını artırdığı veya azalttığı bilinen ilaçların kullanıldığı transplant hastalarında siklosporin düzeyleri sık sık ölçülmeli ve eğer gerekliyse birlikte kullanılacak olan ilacın başlanmasında veya sona erdirilmesi sırasında siklosporin doz ayarlaması yapılmalıdır. Fakat transplantasyon yapılmayan otoimmün hastalarda siklosporin kan düzeyinin izlenmesinin önemi, bu hastalarda kan düzeyi ve klinik etkiler arasındaki ilişki 
yeterli olarak kanıtlanmadığından şüphelidir. Eğer siklosporin düzeylerini artırdığı bilinen ilaçlar birlikte uygulanırsa kan düzeyini ölçmenin yanında sık sık renal fonksiyonun değerlendirilmesi ve siklosporinle ilgili yan etkilerin dikkatli bir şekilde izlenmesi daha uygun olabilir (46-48).

NSAil'lerin takrolimus ile eş zamanlı olarak özellikle yaşı hastalarda kullanıldığında, renal kan akımı ve GFH azalarak nefrotoksisite riskinde artış olasılığı vardır (49). Sıçanlarda yapılmış deneysel bir çalışmada, diklofenak ve rofekoksib ile takrolimusun ikili olarak kombine kullanımlarında, tubuler hücrelerde akut dejeneratif değişiklikler, diklofenak ile daha fazla olmak üzere GFH da bir bozulma ve takrolimus kan düzeylerinde bir azalma görülmüştür (50).

Insanlarda uygulanan metotreksatın, filtrasyon sekresyon ve reabsorbsiyon süreçlerinden geçerek renal eliminasyon yoluyla, verilen dozunun \%80'i değişmeden idrara geçer. Bu eliminasyon süreçlerinde değişikliğe neden olabilecek ilaçlar, potansiyel etkileşimler açısından çok önemlidir (22). Tavşan böbrek kesitlerinde metotreksat birikimini yarışmalı olarak inhibe ettiği gösterilmiş olan (51) NSAil'ler, renal perfüzyonu baskıladığından metotreksatın renal atılımını azaltabilirler. Bu durum NSAil ile metotreksatın birlikte verildiğinde, metotreksat toksisitesinin (nötropeni, trombositopeni, renal disfonksiyon gibi) artabileceğine işaret edebilir $(21,22)$. NSAil'ler ile metotreksatın 3 gün boyunca eşzamanlı uygulamasında dikkatli olunması gereklidir. Hatta NSAil'lerin metotreksat ile tedaviden sonraki 12-24 saatten az bir zaman aralığında verilmemesine dikkat edilmelidir. Aksi takdirde metotreksatın plazma konsantrasyonları yükseleceğinden toksisitesi artabilir $(26,29)$.

Metotreksatın 3 ay boyunca $5-20 \mathrm{mg} /$ hafta şeklinde uygulandığı romatoid artritli hastalarda (52) ve hayvan (53) çalışmalarında, metotreksat farmakokinetiği (plazma veya renal klirens) üzerinde selekoksibin istatistiksel açıdan anlamlı bir etkisi olmamıştır. Fakat söz konusu çalışmalar tüm popülasyonu temsil edecek kadar güçlü değildir ve uzun süreli kullanımları gösteren çalışmalar yeterli değildir (54). NSAil'lerin, tavşan böbrek dokusunda metotreksat birikimini kompetitif olarak inhibe ettiği ve metotreksat toksisitesini artırma intimali olduğu için, bu iki ilaç kombine edildiğinde metotreksatla ilgili toksisite açısından yeterli izlem yapılmalıdır.

İmmünosupresif etkili temel etkili ilaçlardan birisi olan siklofosfamid, indometasin ile birlikte verildiğinde nefrotoksisite artabilir. Bu kullanımda akut su intoksikasyonu da (55) bildirilmiştir. Siklofosfamid toksik etkilerinin görülme sıklığını ve şiddetini arttırdığı bilinen (farmakodinamik ya da farmakokinetik etkileşim yoluyla) diğer madde veya tedavilerin birlikte ya da ardışık kullanımları gerekiyorsa hastaların bireysel olarak beklenen fayda ve risk açısından dikkatle değerlendirilmesi gerekir. Bu tür kombine tedavilerin uygulandığı hastaların, zamanında girişimde bulunabilecek süreye olanak sağlayacak şekilde toksisite işaretleri açısından yakından izlenmesi gerekir. Siklofosfamid ve ilacın aktivasyonunu azaltan ajanları kombine olarak kullanan hastaların ise, terapötik etkinlikte olası bir azalma ve dozun ayarlamasına gerek olup olmadığı açısından yakından izlenmesi gerekir.

Nefrotoksik sinerji gösterebilecek ilaçlarla birlikte kullanımında, renal fonksiyonun (başlıca serum kreatinin) yakın monitörizasyonu yapılmalıdır. Eğer renal fonksiyonda anlamlı bir yetersizlik oluşursa birlikte uygulanan ilacın dozu azaltılmalı veya alternatif bir tedavi dikkate alınmalıdır.

\section{Gastrointestinal Sistem Toksisitesi ile İlişkili Etkileşimler}

Kortikosteroidlerin tek başına kullanımlarına göre, indometazin, aspirin, diklofenak gibi NSAIIlerle birlikte kullanıldığında ciddi gastrointestinal sistem (GiS) advers reaksiyonlarda artış görülebilir (56-59). Özellikle flurbiprofen veya oxaprozin ile GiS ülserasyon ve kanama veya ülserasyon riski artabilir. Kanama belirtileri izlenmelidir.

\section{Enzim Düzeyinin Değişmesi ile İlişkili Etkileşimler}

Selekoksib metabolizması baskın olarak karaciğerde p450 (CYP2C9) aracılığı ile olur. Romatizmal hastalıklarda kullanılan temel etkili ilaçlarla selekoksib arasında enzim düzeyinde bir etkileşim bildirilmemiş ise de CYP2C9 inhibisyonu yaptığı bilinen ilaçlarla birlikte selekoksib kullanıldığında dikkatli olunmalıdır. Bu durumda anlamlı etkileşimler olabilir. Her ne kadar bir substrat olmasa da in vitro çalışmalar selekoksibin bir CYP2D6 inhibitörü olduğunu da göstermiştir. Bu yüzden CYP2D6 aracılı metabolize olan ilaçlar ile invivo ilaç etkileşim potansiyeli de vardır (60).

CYP2C9 ile metabolize olan temel ilaçlardan, leflunomidin invitro çalışmalarda, NSAil ve diğer analjezik ilaçlar ile metotreksat metabolizmaları üzerine bir etkisi olmadığı, söz konusu ilaçlarla birlikte kullanıldığı sınırlı sayıdaki klinik gözlemlerlerde ise bir güvenlik problemi olmadığı bildirilmiştir (61). Fakat leflunomidin NSAil'ler dışında CYP2C9 ile metabolize olan fenitoin, varfarin, fenprokumon ve tolbutamid gibi başka ilaçlarla birlikte kullanımında etkileşme potansiyeline karşı dikkatli olunmalıdır.

\section{Hematolojik Fonksiyonlarla İlişkili Etkileşimler}

Penisillamin, hematolojik (62) ve renal advers reaksiyonlar nedeniyle altın tedavisi, antimalaryal veya sitotoksik ilaçlar, oksifenbutozon veya fenilbutazon ile birlikte alınmamalıdır (63).

\section{Hepatotoksik Etkilerle İlişkili Etkileşimler}

NSAil'ler her yıl 100.000 kişide 3-23 oranında idiosinkratik karaciğer hasarlanmasına yol açabilir $(64,65)$. Hepatotoksik riski en fazla hangi NSAil 
olduğunu belirlemek zor ise de diklofenak, nimesülid ve sulindakı potansiyel hepatotoksik ürünler ile birlikte kullanan kadınlarda risk daha fazladır (66). Öte yandan düzenli alkol tüketimi ve diğer hepatotoksik tıbbi ürünlerle aynı zamanda kullanıldığında metotreksatın karaciğer ile ilişkili yan etki gösterme olasılığı artar. Bu durum başka hepatotoksik tıbbi ürünleri (örn: leflunomid, azatioprin, sülfasalazin) birlikte alan hastalarda da göz önünde bulundurulmalıdır. Leflunomid, metotreksat ile kombine uygulandığında da pansitopeni ve hepatotoksisite insidansı artabilir. TNF- $\alpha$ inhibitör ilaç olan infliksimabın tipik ilaca bağlı otoimmün hepatit yapma potansiyeli olduğu da bilinmektedir ve diğer biyolojik olan DMARD'lerin potansiyel hepatotoksik etkisi yoktur demek de çok mümkün değildir. Söz konusu yan etki potansiyeli olan ilaçların ilave kullanımı hepatotoksik etkiye eğilimi olan ilaçların özellikle de metotreksatın hepatotoksik yan etkilerini artırabilir (67).

Biyolojik etkili antiromatizmal etkili ilaçlarla sınırlı sayıda yapılan farmakokinetik çalışmalarda, sertolizumab ile metotreksat, kortikosteroidler, NSAil gibi analjezikler ile eşzamanlı tedavinin, sertolizumab farmakokinetiğini etkilemediği gösterilmiştir $(68,69)$. Benzer şekildeki klinik denemelerde, Etanersept ile birlikte glukokortikoidler, salisilatlar (sulfasalazin dışında), NSAil'ler analjezikler ve metotreksat kullanıldığında herhangi bir etkileşim rapor edilmemiştir $(70,71)$. Yine erişkin romatoid artritli hastalarda metotreksat, NSAil veya kortikosteroidlerin, tosilizumab klirensi üzerine herhangi bir etkisi saptanmamıştır $(72,73)$.

Sonuç olarak, romatizmal hastalıklarda kullanılan DMARD'lerle analjezik ilaçların etkileşimleri konusunda çalışmalara daha fazla intiyaç olduğu açıktır. Özellikle biyolojik DMARD'lerin klinik kullanımlarından elde edilecek veriler oldukça önemli olacaktır. Kombinasyonlarda sık kullanılma özellikleri de dikkate alındığında, metotreksat ve NSAililer arasında ilaç etkileşimlerine rastlanma olasılıkları yüksektir. Etkileşimlere neden olacak doz aralıkları ve birlikte kullanım şekilleri konusunda iyi bilgilenmek gerekmektedir. Bu kombinasyonlarda doz ve advers etki takipleri ve dikkat çekilmesi adına hasta ile iletişim önemlidir. Özellikle yaşlı, yüksek kardiyovasküler riski olan, böbrek fonksiyonu azalmış veya daha önce böbreklerle ilgili sorunları olan hastalar gibi bireysel risk faktörleri taşıyanların ilaç etkileşimlerine açık olduğu unutulmamalıdır. Ayrıca etkileşim potansiyeli olabilecek DMARD'ler dışında kullanılan başka ilaçların da gözden kaçırılmaması gerekir.

\section{Kaynaklar}

1. Düzgün N. Romatizmal Hastalıkların Tanımı ve Sınıflandırılması. Türkiye Klinikleri J Immunol Rheumatol 2002;2(1):3-5.

2. World Health Organization (Geneva, 1987). The rational use of drugs. Report of the Conference of Experts, Nairobi, 25- 29 November 1985

3. Kayaalp SO. İlaçlar Arasındaki Etkileşmeler. Ed: Kayaalp SO. Akılcı Tedavi Yönünden Tıbbi Farmakoloji. 13. Baskı, 1. Cilt. Pelikan Yayıncılık; 2012:104.

4. Snyder BD, Polasek TM, Doogue MP. Drug interactions: principles and practice. Australian Prescriber 2012;35(3):85-8.

5. Brunton LL, Hilal-Dandan R. İnflamasyon, Ateş, Ağrı ve Gut Farmakoterapisi. Ed: Erdem ŞR. Goodman and Gilman'ın Farmakoloji ve Tedavi El Kitabı 2. Baskı. Güneş Tıp Kitapevleri; 2017:587-613.

6. Smolen JS, Landewé R, Bijlsma J, et al. EULAR recommendations for the management of rheumatoid arthritis with synthetic and biological disease-modifying antirheumatic drugs: 2016 update. Ann Rheum Dis 2017;76(6):960-77.

7. Gülbezer EE, Keser G. Biyolojik tedaviler. RAED Journal 2017;9(1-2):11-31.

8. Keleşoğlu $A B$, Karadağ O. Romatolojik Hastalıklarda Kullanılan İmmünsüpresif İlaçlar (Siklofosfamid, Azatiyopirin, Mikofenolat Mofetil, Takrolimus). Türkiye Klinikleri J Rheumatol-Special Topics 2015;8(3):21-7.

9. Whittle SL, Colebatch AN, Buchbinder R et al. Multinational evidence-based recommendations for pain management by pharmacotherapy in inflammatory arthritis: integrating systematic literature research and expert opinion of a broad panel of rheumatologists in the 3e Initiative. Rheumatology (Oxford). 2012;51(8):1416-25. [PubMed:22447886].

10. Lee YC. Effect and treatment of chronic pain in inflammatory arthritis. Curr Rheumatol Rep 2013;15(1):300. [PubMed:23292816].

11. Bagatini F, Blatt CR, Maliska G et al. Potential drug interactions in patients with rheumatoid arthritis. Rev Bras Reumatol. 2011 Jan-Feb;51(1):20-39. [PubMed: 21412604]

12. Fendrick AM, Pan DE, Johnson GE. OTC analgesics and drug interactions: clinical implications. Osteopath Med Prim Care 2008;2:2. [PubMed: 18257920]

13. Ellison NM, Servi RJ. Acute renal failure and death following sequential intermediate dose methotrexate and 5-FU: a possible adverse effect due to concomitant indomethacin administration. Cancer Treat Rep 1985 Mar;69(3):342 3. [PubMed:3978662]

14. Maiche AG. Acute renal failure due to concomitant action of methotrexate and indomethacin. Lancet 1986;327(8494):1390. [PubMed:2872506]

15. Brogden RN. Nonsteroidal anti-inflammatory analgesics other than salicylates. Drugs 1986;32 (Suppl 4):27-45. [PubMed: 3552584]

16. Thyss A, Milano G, Kubar J, Namer M, Schneider M. Clinical and pharmacokinetic evidence of a life-threatening interaction between methrotrexate and ketoprofen. Lancet 1986; 327(8475):256-8 [PubMed: 2868265]

17. Singh RR, Malaviya AN, Pandey JN. Guleria JS. Fatal interaction between methotrexate and naproxen. Lancet 1986; 327(8494):1390 [PubMed:2872507]

18. Adams JD, Hunter GA. Drug interactions in psoriasis. Australas J Dermatol 1976;17(2):39-40. [PubMed:1022213]

19. Daly H, Boyle J, Roberts C, Scott G. Interaction between methotrexate and nonsteroidal anti-inflammatory drugs. Lancet 1986 327(8480): 557 [PubMed: 2869282]

20. Liegler DG, Henderson ES, Hahn MA, Oliverio VT. The effect of organic acids on renal clearance of methotrexate in man. Clin Pharmacol Ther 1969;10(6):849-57. [PubMed:5349626] 
21. Bannwarth B, Péhourcq F, Schaeverbeke T, Dehais J. Clinical pharmacokinetics of low-dose pulse methotrexate in rheumatoid arthritis. Clin Pharmacokinet 1996;30(3):194-210. [PubMed:8882301]

22. Statkevich P, Fournier DJ, Sweeney KR. Characterization of methotrexate elimination and interaction with indomethacin and flurbiprofen in the isolated perfused rat kidney. J Pharmacol Exp Ther 1993;265(3):1118-24. [PubMed: 8509997]

23. Takeda M, Khamdang S, Narikawa $S$ et al. Characterization of methotrexate transport and its drug interactions with human organic anion transporters. J Pharmacol Exp Ther 2002;302(2):666-71. [PubMed: 12130730]

24. Uwai $Y$, Saito H, Inui K. Interaction between methotrexate and nonsteroidal anti-inflammatory drugs in organic anion transporter. Eur J Pharmacol 2000;409(1):31-6. [PubMed:11099697]

25. Stewart CF, Fleming RA, Arkin CR, Evans WE. Coadministration of naproxen and low-dose methotrexate in patients with rheumatoid arthritis. Clin Pharmacol Ther 1990;47(4):540-6. [PubMed:2328562]

26. Johnson AG, Seideman P, Day RO. Adverse drug interactions with nonsteroidal anti-inflammatory drugs (NSAIDs). Recognition, management and avoidance. Drug Saf. 1993;8(2):99-127. [PubMed:8452660]

27. Stewart CF, Evans WE. Drug-drug interactions with antirheumatic agents: review of selected clinically important interactions. J Rheumatol Suppl 1990;22:16-23 [PubMed: 2192056]

28. Weinblatt ME. Drug interactions with non-steroidal anti-inflammatory drugs (NSAIDs). Scand J Rheumatol Suppl 1989;83:7-10. [PubMed: 2576330]

29. Fischetti LF. Interaction between nonsteroidal anti-inflammatory drugs and high-dose methotrexate: a literature review. J Pediatr Oncol Nurs 1990;7(1):14-6 [PubMed:2194502]

30. Colebatch AN, Marks JL, Edwards CJ. Safety of non-steroidal anti-inflammatory drugs, including aspirin and paracetamol(acetaminophen) in people receiving methotrexate for inflammatory arthritis (rheumatoid arthritis, ankylosing spondylitis, psoriatic arthritis, other spondyloarthritis). Cochrane Database Syst Rev 2011;11:CD008872. [PubMed:22071858]

31. Lifschitz MD. Prostaglandins and renal blood flow: in vivo studies. Kidney Int 1981;19(6):781-5. [PubMed:6790809]

32. Clive DM, Stoff JS. Renal syndromes associated with nonsteroidal antiinflammatory drugs. N Engl J Med. 1984;310(9):563-72. [PubMed: 6363936]

33. Schnermann J, Briggs JP. Participation of renal cortical prostaglandins in the regulation of glomerular filtration rate. Kidney Int 1981;19(6):802-15. [PubMed:7021955]

34. Dunn MJ, Simonson M, Davidson EW, Scharschmidt LA, Sedor JR. Nonsteroidal anti-inflammatory drugs and renal function. $J$ Clin Pharmacol 1988;28(6):524-9. [PubMed:3047178]

35. Blackshear JL, Napier JS, Davidman M, Stillman MT. Renal complications of nonsteroidal antiinflammatory drugs: identification and monitoring of those at risk. Semin Arthritis Rheum. 1985;14(3):163-75. [PubMed:3909403]

36. Deray G, Le Hoang P, Aupetit B, Achour A, Rottembourg J, Baumelou A. Enhancement of cyclosporine A nephrotoxicity by diclofenac. Clin Nephrol. 1987;27(4):213-4. [PubMed:2953512]

37. Sturrock ND, Lang CC, Struthers AD. Indomethacin and cyclosporin together produce marked renal vasoconstriction in humans. J Hypertens. 1994;12(8):919-24. [PubMed:7814851]

38. Olyaei AJ, de Mattos AM, Bennett WM. Immunosuppressant induced nephropathy: pathophysiology, incidence and management. Drug Saf. 1999;21(6):471-88. [PubMed:10612271]

39. Altman RD, Perez GO, Sfakianakis GN. Interaction of cyclosporine A and nonsteroidal anti-inflammatory drugs on renal function in patients with rheumatoid arthritis. Am J Med. 1992;93(4):396-402. [PubMed:1415303]

40. Harris KP, Jenkins D, Walls J. Nonsteroidal antiinflammatory drugs and cyclosporine. A potentially serious adverse interaction. Transplantation. 1988;46(4):598-9. [PubMed:3176159]

41. Williamson HE. Interaction of cyclosporine and indomethacin in the rat. Res Commun Chem Pathol Pharmacol. 1988;61(1):141 4. [PubMed:3262905]

42. Helmy MW, El-Gowelli HM, Ali RM, El-Mas MM. Endothelin ETA receptor/lipid peroxides/COX-2/TGF- $\beta 1$ signalling underlies aggravated nephrotoxicity caused by cyclosporine plus indomethacin in rats. $\mathrm{Br} \mathrm{J}$ Pharmacol. 2015;172(17):4291-302. [PubMed:26013701]

43. Kovarik JM, Mueller EA, Gerbeau C, Tarral A, Francheteau P, Guerret M. Cyclosporine and nonsteroidal antiinflammatory drugs: exploring potential drug interactions and their implications for the treatment of rheumatoid arthritis. Life Sci 2017 Sep 15:185:15-22

44. El-Gowelli HM, Ibrahim KS, El-Yazbi AF, El-Mas M.M. Role of NADPHox/Rho-kinase signaling in the cyclosporine-NSAIDs interactions on blood pressure and baroreflexes in female rats. J Clin Pharmacol. 1997;37(4):336-43. [PubMed:9115060]

45. El-Yazbi AF, Eid AH, El-Mas MM. Cardiovascular and renal interactions between cyclosporine and NSAIDs: Underlyingmechanisms and clinical relevance. Pharmacol Res. 2018;129:251-261. [PubMed:29183768]

46. Kahan BD, Keown P, Levy GA, Johnston A. Therapeutic drug monitoring of immunosuppressant drugs in clinical practice. Clin Ther. 2002;24(3):330-50. [PubMed:11952020]

47. Campana C, Regazzi MB, Buggia I, Molinaro M. Clinically significant drug interactions with cyclosporin. An update. Clin Pharmacokinet. 1996;30(2):141-79. [PubMed:8906896]

48. Ludwin D. Cyclosporine monitoring in autoimmune and other diseases. Clin Biochem. 1991;24(1):97-9. [PubMed:2060141]

49. Naesens M, Lerut E. Calcineurin Inhibitor Nephrotoxicity in the Era of Antibody-Mediated Rejection. Transplantation. 2016;100(8):1599-600. [PubMed:27306528]

50. Soubhia RM, Mendes GE, Mendonça FZ, Baptista MA, Cipullo JP, Burdmann EA. Tacrolimus and nonsteroidal antiinflammatory drugs: an association to be avoided. Am J Nephrol. 2005;25(4):327-34. [PubMed:15976495]

51. Nierenberg DW. Competitive inhibition of methotrexate accumulation in rabbit kidney slices by nonsteroidal anti-inflammatory drugs. J Pharmacol Exp Ther. 1983;226(1):1-6. [PubMed:6864533]

52. Karim A, Tolbert DS, Hunt TL, Hubbard RC, Harper KM, Geis GS. Celecoxib, a specific COX-2 inhibitor, has no significant effect on methotrexate pharmacokineticsin patients with rheumatoid arthritis. J Rheumatol. 1999;26(12):2539-43. [PMID:10606360]

53. Maeda A, Tsuruoka S, Ushijima K et al. Drug interaction between celecoxib and methotrexate in organic anion transporter 3transfectedrenal cells and in rats in vivo. Eur J Pharmacol. 2010;640(1-3):168-71. [PubMed:20478302]

54. Davies NM, McLachlan AJ, Day RO, Williams KM. Clinical pharmacokinetics and pharmacodynamics of celecoxib: a selective cyclo-oxygenase-2inhibitor. Clin Pharmacokinet. 2000;38(3):225-42. [ PubMed:10749518]

55. Webberley MJ, Murray JA. Life-threatening acute hyponatraemia induced by low dose cyclophosphamide and indomethacin Postgrad Med J. 1989;65(770):950-2. [PubMed:2616440]

56. Raschi E, Piccinni C, Signoretta V et al. Clinically important drug-drug interactions in poly-treated elderly outpatients: a campaign to improve appropriateness in general practice. Br J Clin Pharmacol. 2015;80(6):1411-20. [PubMed:26303150] 
57. Masclee GM, Valkhoff VE, Coloma PM et al. Risk of upper gastrointestinal bleeding from different drug combinations. Gastroenterology. 2014;147(4):784-792. [PubMed:24937265]

58. Bijlsma JW, Boers M, Saag KG, Furst DE. Glucocorticoids in the treatment of early and late RA. Ann Rheum Dis. 2003;62(11):1033-7. [PubMed:14583563]

59. Bertsche T, Mikus G. Adverse drug reactions and drug interactions in analgesic therapy. Ther Umsch. 2011;68(1):19-26 [PubMed:21184390]

60. Siu YA, Hao MH, Dixit V, Lai WG. Celecoxib is a substrate of CYP2D6: Impact on celecoxib metabolism in individuals with CYP2C9*3 variants. Drug Metab Pharmacokinet. 2018 Oct;33(5):219-227. [PubMed:30219715]

61. Rozman B. Clinical pharmacokinetics of leflunomide. Clin Pharmacokinet. 2002;41(6):421-30. [PubMed:12074690]

62. Stobbe H, Hüge W. Hematotoxic lesions caused by non-steroidal antirheumatic agents. Z Gesamte Inn Med. 1980;35(23):1659. [PubMed:7467611]

63. U.S. Food and Drug Administration. CUPRIMINE® (Penicillamine). 2004. MERCK\&CO. INC. Whitehouse Station, NJ 08889, USA. https://www.accessdata.fda.gov/drugsatfda_docs/label/2004/19853s012,014lbl.pdf

64. Rubenstein JH, Laine L. Systematic review: the hepatotoxicity of non-steroidal anti-inflammatory drugs. Aliment Pharmacol Ther. 2004;20(4):373-80. [PubMed:15298630]

65. Aithal GP, Day CP. Nonsteroidal anti-inflammatory drug-induced hepatotoxicity. Clin Liver Dis. 2007;11(3):563-75. [PubMed:17723920]

66. Pérez Gutthann S, García Rodríguez LA. The increased risk of hospitalizations for acute liver injury in a population with exposure to multiple drugs. Epidemiology. 1993;4(6):496-501. [PubMed:8268277]

67. Anelli MG, Scioscia C, Grattagliano I, Lapadula G. Old and new antirheumatic drugs and the risk of hepatotoxicity. Ther Drug Monit. 2012 Dec;34(6):622-8.

68. U.S Food and Drug Administration. CIMZIA® (Certolizumab pegol) 2018. UCB INC. Smyrna, GA 30080, USA https://www.accessdata.fda.gov/drugsatfda_docs/label/2018/125160s283lbl.pdf.

69. The electronic Medicines Compendium (eMC) CIMZIA® (Certolizumab pegol) 2018. UCB Pharma Limited, Slough, Berkshire, SL1 3WE, UK. https://www.medicines.org.uk/emc/product/7387/smpc.

70. U.S Food and Drug Administration. ENBREL $($ Etanercept) 2018. AMGEN INC. Thousand Oaks, CA 91320-1799, USA https://www.accessdata.fda.gov/drugsatfda_docs/label/2018/103795s5569lbl.pdf.

71. The electronic Medicines Compendium (eMC) BENEPALI® (Etanercept) 2018. Biogen Idec Ltd. Maidenhead, Berkshire, SL6 4AY, UK. https://www.medicines.org.uk/emc/product/1987/smpc.

72. U.S Food and Drug Administration. ACTEMRA® (Tocilizumab) 2018. GENENTECH INC. South San Francisco, CA 940804990, USA. https://www.accessdata.fda.gov/drugsatfda_docs/label/2018/125276s118,125472s029lbl.pdf.

73. The electronic Medicines Compendium (eMC) ROACTEMRA® (Tocilizumab) 2018 ROCHE Product Limited, Welwyn Garden City, Hertfordshire, AL7 1TW, UK. https://www.medicines.org.uk/emc/product/9086/smpc. 